\title{
ESCOLA NA OU DA PRISÃO?
}

\author{
Elionaldo Fernandes Julião $0^{1}$
}

\begin{abstract}
RESUMO: Embora algumas experiências estaduais de educação para jovens e adultos em situação de restrição e privação de liberdade remontem há algumas décadas, somente a partir de 2005 é que se iniciam no Brasil encaminhamentos para implementação de uma política propriamente nacional, quando os Ministérios da Educação e da Justiça iniciaram uma proposta de articulação para implementação de Programa Nacional de Educação para o Sistema Penitenciário, formulando as suas diretrizes. Fundamentado em uma concepção crítica sobre o papel do sistema penitenciário na sociedade contemporânea, analisando as suas perspectivas políticas e pedagógicas, principalmente articulando os conceitos de garantias de direitos, políticas públicas, incompletude institucional e socialização, este artigo se propóe a investir na discussáo sobre o papel da educação no sistema penitenciário, mais precisamente sobre a escola localizada no espaço carcerário.
\end{abstract}

Palavras-chave: Educação de jovens e adultos. Educação nas prisóes. Socialização.

\section{School in prison or school prison?}

ABSTRACT: Although some state educational experiences for youth and adults in situations of liberty restriction or deprivation go back a few decades; only in 2005 Brazil starts to see the implementation of proper national policies. In that year, the Ministries of Education and Justice initiated a joint proposal

${ }^{1}$ Universidade Federal Fluminense, Instituto de Educação de Angra dos Reis - Angra dos Reis (RJ), Brasil. E-mail: elionaldoj@yahoo.com.br

DOI: 10.1590/CC0101-32622016162554 
for the implementation of the National Education Program for the Penitentiary System, formulating its guidelines. This article relies on the critical conception of the prison system's role in contemporary society, and analyzes its political and pedagogical perspectives, especially articulating the concepts of right guarantees, public policies, institutional incompleteness and socialization. It also proposes to enforce the discussion on the role of education in the prison system, more precisely on the school located in the prison space.

Keywords: Youth and adult education. Education in prisons. Socialization.

\section{ESCOLA NA OU DA PRISÃO?}

A

história das primeiras experiências de educação para jovens e adultos no sistema penitenciário remonta a algumas décadas. Muitas delas surgiram através de experiências isoladas em unidades penais, promovidas por voluntários que se sensibilizavam com a situação dos apenados. Mobilizados por questóes de fé ou de ordem ideológica, representantes religiosos ou de organizaçóes náo governamentais, agregando suas açóes assistenciais, desenvolviam projetos pontuais de alfabetização em espaços improvisados, sem qualquer apoio dos gestores locais, bem como do próprio Estado.

Dessas pequenas experiências pontuais, voluntariosas, improvisadas, alguns estados da federação aos poucos regulamentaram determinados projetos, incorporando a demanda às escolas próximas das unidades penais, como turmas em espaços anexos, ou assumindo a sua coordenação, incorporando profissionais do sistema — muitos sem qualquer experiência no magistério - e/ou internos do próprio sistema penitenciário para ministrar aulas para os seus colegas apenados.

O Rio de Janeiro, por exemplo, em 1967, inicia oficialmente, através de convênio entre a então Secretaria de Estado de Justiça e a Secretaria de Estado de Educação, uma experiência pioneira com escolas exclusivas em algumas unidades penais para oferecimento de açóes de 
alfabetização e de elevação de escolaridade - principalmente de ensino fundamental (JULIÃO, 2003).

Em Sáo Paulo, através da Fundação Prof. Dr. Manoel Pedro Pimentel (FUNAP), em décadas subsequentes, algumas unidades do sistema penitenciário passam a contar com aulas regulares de alfabetização e também de elevação de escolaridade ministradas por internos penitenciários para os seus próprios colegas ${ }^{1}$ (PENNA, 2007; LEME, 2007).

De norte a sul do país, é possível se ouvir falar de experiências isoladas que foram se consolidando com o tempo em açóes públicas de educação para jovens e adultos no sistema penitenciário. Assim, aos poucos, vão surgindo escolas nas unidades penais que oferecem desde aulas de alfabetização, de ensino fundamental, até de ensino médio ${ }^{2}$ em todo o país (JULIÃO, 2003).

Atendendo ao previsto na Lei de Execução Penal (BRASIL, 2011a), ao longo dessa história de idas e vindas, pequenos sistemas de ensino são organizados em alguns estados para garantir a escolarização de jovens e adultos apenados. Porém, em outros, as experiências voluntariosas ainda permanecem como única alternativa.

Em 2005, após longas décadas de experiências diversas de educação no cárcere, o Ministério da Educação, através da sua então recém criada Secretaria de Educação Continuada, Alfabetização e Diversidade (SECAD), assume o tema como uma das suas demandas na política de educação (UNESCO, 2006).

Com anos de atraso, através do Projeto Educando para a Liberdade, com o apoio da Unesco, é criado um grupo de trabalho com representantes dos Ministérios da Educação (SECADI/MEC), do Departamento Penitenciário Nacional do Ministério da Justiça e de representantes estaduais e pesquisadores para se iniciar um processo de discussão para implementação de uma política nacional de educação para jovens e adultos nos cárceres brasileiros.

Após vários encontros regionais e dois seminários nacionais (2006 e 2007) para se discutir o tema "educação nas prisóes", são aprovadas, respectivamente, nos anos de 2009 e 2010, as Diretrizes Curriculares Nacionais para a Educação no Sistema Prisional pelo Conselho Nacional 
de Política Criminal e Penitenciária (CNPCP) e Conselho Nacional de Educação (CNE) (UNESCO, 2009).

A partir de então, espera-se que os estados, através das suas secretarias estaduais de educação, assumam a política de educação para jovens e adultos em situação de privação de liberdade, reconhecendo-a não mais como uma ação pontual, isolada, voluntária, mas sim como uma política pública de educação.

Vários são os avanços nessa direção. Além das diretrizes nacionais para a oferta de educação para jovens e adultos em situação de privação de liberdade (Resoluções CNPCP no 3, de 2009 - CNPCP, 2009 - e CNE no 2, de 2010 - CNE, 2010), foram aprovadas a Lei $\mathrm{n}^{\circ} 12.433 / 2011$ (BRASIL, 2011a), que dispóe sobre a remiçâo de parte do tempo de execução da pena por estudo ou por trabalho; as diretrizes básicas para arquitetura prisional (Resolução CNPCP no 09 - CNPCP, 2011), que determina previsão de módulos educativos, laborais, de esporte e de lazer na construção de novas unidades penais; o Decreto Presidencial no 7.626 (BRASIL, 2011b) que institui o Plano Estratégico de Educação no Âmbito Prisional; assim como a presença do tema nas discussóes e documentos finais aprovados nas Conferências Nacionais de Educação Básica (BRASIL, 2008) e de Educação (BRASIL, 2010; 2014a) e no Plano Nacional de Educação 2014 - 2024 (BRASIL, 2014b).

Em ambos os documentos aprovados nos últimos anos, reconhece-se que a educação para jovens e adultos no cárcere não é benefício, como algumas pessoas ainda acreditam, mas sim direito previsto em Lei - Constituição Federal (BRASIL, 1988), Lei de Diretrizes e Bases da Educação Nacional (LDBEN) (BRASIL, 1996) e Lei de Execução Penal (BRASIL, 1984). A educação, em síntese, conforme os nossos marcos legais, é um direito público e subjetivo e sua oferta escolar deve estar adequa$\mathrm{da}$ às necessidades e disponibilidades dos seus sujeitos, garantindo sob qualquer coisa, condiçóes de acesso e permanência na escola (JULIÂO, 2015).

Embora se reconheça como direito do preso a educação, ainda poucos têm acesso. Segundo dados divulgados pelo Ministério da Justiça, em 2015, referentes a 2014, apenas $58.750(10,92 \%)$ dos apenados no país estavam participando de alguma atividade educativa no cárcere. Embora tenha crescido quase $40 \%$ o número de matrículas de 2008 a 2013, diminui-se 
percentualmente o número de apenados atendidos, visto que o crescimento do número de presos tem ultrapassado 5\% anualmente (BRASIL, 2015).

Assim como reconhecemos importantes avanços na consolidação da política, também tivemos no campo dos estudos acadêmicos. Ao longo da última década, várias dissertações e teses foram produzidas em todo o país em Programas de Pós-graduação em Educação, Ciências Humanas e Sociais refletindo sobre o tema.

Chegamos em um momento em que precisamos efetivamente avançar na discussão, ampliando as nossas reflexóes sobre a política implementada. Visando contribuir nessa direção, este artigo, fundamentado em uma concepção crítica sobre o papel do sistema penitenciário na sociedade contemporânea, tem como objetivo analisar as suas perspectivas políticas e pedagógicas, principalmente articulando os conceitos garantias de direitos, políticas públicas, incompletude institucional e socialização. Em linhas gerais, propóe-se a investir na discussão sobre o papel da educação no sistema penitenciário, mais precisamente sobre a escola localizada no espaço carcerário.

\section{SOBRE A POLÍTICA DE EDUCAÇÃO NO CÁRCERE}

A Constituição Federal (Art. 205) estabelece que a educação é um direito de todos visando ao pleno desenvolvimento da pessoa, seu preparo para o exercício da cidadania e sua qualificação para o trabalho (BRASIL, 1988).

De acordo com a Lei de Diretrizes e Bases da Educação, Lei no 9.394 (BRASIL, 1996), a educação para jovens e adultos é uma modalidade da educação básica e "será destinada àqueles que não tiveram acesso ou continuidade de estudos no ensino fundamental e médio na idade própria", sendo-lhes asseguradas "oportunidades educacionais apropriadas, consideradas as características do alunado, seus interesses, condiçóes de vida e de trabalho, mediante cursos e exames" (Art. 37).

Nessa direção, conforme o Art. 83 da Lei de Execução Penal brasileira (BRASIL, 1984), todo "estabelecimento penal, conforme a sua natureza, deverá contar em suas dependências com áreas e serviços destinados a dar assistência, educaçáo, trabalho, recreação e prática esportiva”. 
No seu Art. 10 do Capítulo II - Da Assistência, afirma que “a assistência ao preso e ao internado é dever do Estado, objetivando prevenir o crime e orientar o retorno à convivência em sociedade". Para tanto, será: material, à saúde, jurídica, educacional, social e religiosa.

Da Assistência Educacional, Artigos 17 a 21, diz que "compreenderá a instrução escolar e a formação profissional do preso e do internado" e que "o ensino de primeiro grau (atual ensino fundamental) ${ }^{3}$ será obrigatório, integrando-se no sistema escolar da unidade federativa”. Já o ensino profissional deverá ser ministrado em nível de iniciação ou de aperfeiçoamento técnico.

Em atendimento às condições locais, institui que todas as unidades deverão dotar-se de uma biblioteca provida de livros instrutivos, recreativos e didáticos e que, devido à abrangência e particularidade da questão, as atividades educacionais podem ser objeto de convênio com entidades públicas ou particulares, instalando escolas ou oferecendo cursos especializados.

Através das Resoluções CNPCP no 3 (CNPCP, 2009) e CNE no 2 (CNE, 2010), são aprovadas as Diretrizes Nacionais para oferta de educação para jovens e adultos em situação de privação de liberdade nos estabelecimentos penais. Assim, ficam garantidas que as ações de educação em contexto de privação de liberdade devem estar calcadas na legislação educacional vigente no país, na Lei de Execução Penal, nos tratados internacionais firmados pelo Brasil no âmbito das políticas de direitos humanos e privação de liberdade, devendo atender às especificidades dos diferentes níveis e modalidades de educação e ensino e são extensivas aos presos provisórios, condenados, egressos do sistema prisional e àqueles que cumprem medidas de segurança (Art. 20 da CNE no 2 - CNE, 2010).

A sua oferta, segundo os documentos, deve ser garantida (Art. 30 da CNE no 2 - CNE, 2010) pelo órgão responsável pela educação nos estados e no Distrito Federal (Secretaria de Educação ou órgão equivalente) e deverá ser realizada em articulação com os órgãos responsáveis pela sua Administração Penitenciária, exceto nas penitenciárias federais, cujos programas educacionais estarão sob a responsabilidade do Ministério da Educação em articulação com o Ministério da Justiça, que poderá celebrar convênios com estados, Distrito Federal e municípios. 
Após anos de discussão no Congresso Nacional, em junho de 2011 foi aprovada a Lei no 12.433 (BRASIL, 2011a) que altera a Lei de Execução Penal, Lei no 7.210 (BRASIL, 1984), para dispor sobre a remição de parte do tempo de execução da pena por estudo ou por trabalho. Assim, assumindo a educação também como prática ressocializadora no programa político público de execução penal, garante-se ao condenado que cumpre a pena em regime fechado ou semiaberto remir, tanto pelo trabalho como pelo estudo, parte do tempo de execução da pena.

Nesse mesmo ano, o Conselho Nacional de Política Criminal e Penitenciária, através das suas Diretrizes Básicas para Arquitetura Penal (Resolução CNPCP no 9 - CNPCP, 2011), também determinou que os estabelecimentos penais deverão prever na construção, ampliação e reforma de estabelecimentos penais em parceria com o Governo Federal, conforme o caso e o uso a que se destina o estabelecimento, os módulos conforme o programa de necessidades, atendendo atividades, dentre outras, educativas, laborais, esportivas e de lazer.

Também em 2011 foi aprovado o Decreto Presidencial $n^{\circ}$ 7.626 (BRASIL, 2011b), que institui o Plano Estratégico de Educação no âmbito do Sistema Prisional com a finalidade de ampliar e qualificar a oferta de educação nos estabelecimentos penais. Dentre os seus objetivos (Art. $4^{\circ}$ ), destacam-se:

(I) executar ações conjuntas e troca de informações entre órgãos federais, estaduais e do Distrito Federal com atribuiçóes nas áreas de educação e de execução penal;

(II) incentivar a elaboração de planos estaduais de educação para o sistema prisional, abrangendo metas e estratégias de formação educacional da população carcerária e dos profissionais envolvidos em sua implementação;

(III) contribuir para a universalização da alfabetização e para a ampliação da oferta da educação no sistema prisional;

(IV) fortalecer a integração da educação profissional e tecnológica com a educação de jovens e adultos no sistema prisional; 
(V) promover a formação e capacitação dos profissionais envolvidos na implementação do ensino nos estabelecimentos penais; e

(VI) viabilizar as condiçóes para a continuidade dos estudos dos egressos do sistema prisional.

O documento destaca ainda que para o alcance dos objetivos previstos (Parágrafo único do Art. $4^{\circ}$ )

serão adotadas as providências necessárias para assegurar os espaços físicos adequados às atividades educacionais, culturais e de formação profissional, e sua integração às demais atividades dos estabelecimentos penais.

No campo legal, sem sombra de dúvida, o Brasil é reconhecido internacionalmente por sua legislação. Os avanços normativos para a política de restrição e privação de liberdade têm sido analisados como muito positivos por vários países da América Latina, inclusive sendo referência para as suas discussôes. Como concepção, é reconhecida como inovadora, pois se fundamenta em uma perspectiva moderna de execuçáo penal que reconhece os sujeitos apenados como cidadãos e garantidores de direitos.

A aprovação das suas Diretrizes Nacionais para oferta de educação para jovens e adultos em situação de privação de liberdade nos estabelecimentos penais, por exemplo, foi reconhecida pelos países integrantes da Rede Latino Americana de Educação em Contexto de Encarceramento (RedLece) como um documento inovador a ser seguido, como concepção, pelos países membros.

Saindo do âmbito legal para efetivação da política na prática, infelizmente não podemos nos vangloriar dos nossos feitos. Ao contrário de alguns países, como a Argentina, por exemplo, que além da educação básica no cárcere possui experiências consolidadas de ensino superior há décadas em algumas unidades prisionais, o Brasil, além de não ter saído das experiências de educaçáo básica — muitas ainda sendo realizadas precariamente — ainda amarga com um número elevado de jovens e adultos encarcerados analfabetos e/ou que náo concluíram o ensino fundamental sem acesso aos bancos escolares. 
Infelizmente, não diferente das políticas sociais em geral no nosso país, vivemos também na política de educação para os jovens e adultos em situação de restrição e privação de liberdade as contradiçóes e agruras do descompasso entre o legal e o instituído na prática, tão comum na cultura política do nosso Estado.

Os nossos marcos legais reconhecem hoje a diversidade dos sujeitos da educação de jovens e adultos e lhes garantem a educação como direito humano fundamental e subjetivo. Assim, a educação implementada no ambiente carcerário, como modalidade da educação básica para jovens e adultos, deve investir em uma proposta política e pedagógica que leve em consideração as particularidades, especificidades e características dos sujeitos apenados.

\section{SOBRE O PAPEL DA EDUCAÇÃO NO CÁRCERE}

É senso comum, na prática, reduzir o papel da educação escolar para as classes populares à elevação de escolaridade, primando-se por um currículo com caráter mais instrumental, conteudista, visando eminentemente à sua inserção no mercado de trabalho. Por outro lado, a nossa Constituição Federal (BRASIL, 1988) e a LDBEN (BRASIL, 1996), promulgam que cabe à educação "o pleno desenvolvimento da pessoa e seu preparo para o exercício da cidadania”. O que a legislação propóe, portanto, é que a formação para o mundo do trabalho é uma das práticas sociais que garante a formação integral dos sujeitos (LDBEN, Art. $\left.1^{\circ}, \S 2^{\circ}\right)$.

Por outro lado, tomando-se a perspectiva da Lei de Execução Penal (BRASIL, 1984), o papel da educação no cárcere é de ressocializar o apenado. Ou seja, "compreenderá a instrução escolar e a formação profissional do preso e do internado" (Art. 17), que, com as demais assistências, deverá ter como objetivo "prevenir o crime e orientar o retorno à convivência em sociedade"(Art. 10), promovendo a sua reintegração social.

Através de diversos estudos realizados sobre a educação implementada no sistema penitenciário brasileiro (JULIÃO; PAIVA, 2015), a educação é considerada como um dos meios de promover a integração social e a aquisição de conhecimentos que permitam aos reclusos assegurar 
um futuro melhor quando recuperar a liberdade. Essa posição talvez seja compartilhada pelos apenados que compreendem que o encarceramento tem uma finalidade que vai além do castigo, da segregação e dissuasão e que, portanto, aceitam voluntariamente e aprovam o aspecto reformador do encarceramento, em especial as atividades de educação profissional e as informaçóes sobre oportunidades de emprego. Outros apenados, ao contrário, rechaçam a educação como parte de um sistema impositivo e castrador, que os querem alienados. Sem dúvida alguma, por outro lado, é possível ainda que muitos apenados participem inicialmente das atividades educativas por razóes alheias à educação, como, por exemplo: sair das suas celas, estar com amigos ou evitar o trabalho etc.

Como também já evidenciado em alguns estudos, a educação em espaços de privação de liberdade pode ter principalmente três objetivos imediatos que refletem as distintas opinióes sobre a finalidade do sistema de justiça penal: manter os reclusos ocupados de forma proveitosa; melhorar a qualidade de vida na prisão; e conseguir um resultado útil, tal como ofícios, conhecimentos, compreensão, atitudes sociais e comportamento, que perdurem além da prisão e permitam ao apenado o acesso ao emprego ou a uma capacitaçáo superior, que, sobretudo, propicie mudanças de valores, pautando-se em princípios éticos e morais. Essa educação pode ou não se reduzir ao nível da reincidência. Já os demais objetivos formam parte de um objetivo mais amplo que a reintegração social e o desenvolvimento do potencial humano (JULIÂO, 2012).

Levando-se em consideração que o cárcere, dentre os seus objetivos, tem o papel de reinserção social do apenado, deverá estar estruturado de forma que possibilite, a qualquer custo, garantir os direitos fundamentais do interno (integridade física, psicológica e moral), viabilizando a sua permanência de forma digna e capacitando-lhe para o convívio social e para o seu desenvolvimento pessoal e social.

\section{SOBRE A POLÍTICA DE EDUCAÇÃO IMPLEMENTADA NO CÁRCERE}

É muito comum, ainda dentro de uma perspectiva retrógrada de educação supletiva e de correção de fluxo, assumir a Educação de 
Jovens e Adultos (EJA) como redução de conteúdos previstos para a educação regular básica, não se pensando propriamente em um currículo que atenda às especificidades e características dos seus sujeitos jovens, adultos e idosos.

Durante muitos anos, quando se falava em educação para jovens e adultos, imaginava-se estar falando de um grupo social homogêneo com características biopsicossociais bem distintas dos demais e definidas. Não se levava em consideração as suas particularidades, especificidades, tampouco a sua diversidade: faixa etária; gênero; etnia; credo religioso; ocupação profissional; orientação sexual; situação social; e se privados ou não de liberdade (JULIÃO, 2015).

Com os avanços instituídos na área nos últimos anos, principalmente no âmbito do reconhecimento do direito humano fundamental em que se constitui a Educação em seu papel na sociedade contemporânea, a necessidade de compreensão dessas particularidades, para se levar em consideração as propostas político-pedagógicas, traz como primordial a compreensão sobre os sujeitos da EJA.

Recentes discussões no campo da EJA defendem a necessidade de uma maior adequação à proposta de ensino implementada para os seus sujeitos, reconhecendo a sua diversidade. Na busca pela compreensão dos atuais sujeitos da EJA, passou-se a identificar que estamos falando de um campo muito diverso, com muitas particularidades, especificidades e armadilhas. Hoje, principalmente, necessitamos compreender melhor essa modalidade de ensino diante da diversidade do público.

No contexto da discussão sobre a diversidade dos sujeitos da EJA, a educação nas prisóes efetivamente passa a ser reconhecida como educação para jovens e adultos, sendo, assim, necessário um investimento em uma proposta política e pedagógica que leve em consideração as particularidades, especificidades e características dos sujeitos em situação de restrição e privação de liberdade.

Contrariando tal perspectiva, grande parte das experiências de educação no sistema penitenciário brasileiro ainda segue um modelo tradicional de ensino regular para jovens e adultos encarcerados. Geralmente, com poucas exceções, acabam levando para o cárcere experiências de educação implementadas extramuros. Ou seja, reproduz-se no 
cárcere uma escola padronizada que pouco dialoga com as especificidades dos seus sujeitos.

As experiências de educação no cárcere, não diferentes de muitas de educação de jovens e adultos extramuros, são geralmente meras reproduçóes de uma educação regular para crianças. Poucas são as que se efetivam como modalidade de ensino prevista na LDBEN (Artigos 37 e 38). São geralmente experiências com propostas pedagógicas descontextualizadas da realidade do sistema prisional. São escolas que — por um acaso - estáo na prisão.

Compreendendo a educação como o único processo capaz de transformar o potencial das pessoas em competências, capacidades e habilidades - o mais (saúde, alimentação, integridade física, psicológica e moral) são condiçóes para a efetivação da ação educativa - e educar como o ato de criar espaços para que o educando, situado organicamente no mundo, empreenda a construção do seu ser em termos individuais e sociais, o espaço carcerário (de privação de liberdade), com todas as suas idiossincrasias, deve ser entendido como um espaço educativo, ambiente socioeducativo. Assim sendo, todos que atuam nessas unidades (pessoal dirigente, técnico, professor e operacional) são educadores (socioeducadores) e devem, independente da sua função, estar orientados nessa condiçấo. Todos os recursos e esforços devem convergir, com objetividade e celeridade, para o trabalho educativo. Ou seja, todas as unidades devem possuir um Projeto Político Institucional que oriente as açóes, defina os recursos e viabilize uma atuação consciente e consistente com o plano individual de trabalho ${ }^{4}$ do interno.

As açôes educativas devem exercer uma influência edificante na vida do interno, criando condiçôes para que molde sua identidade, buscando, principalmente, compreender-se e aceitar-se como indivíduo social; e construir seu projeto de vida, definindo e trilhando caminhos para a sua vida em sociedade. Assim como deve existir educação escolar e a educação profissional dentro do espaço carcerário como política de execução penal, hoje, também defendemos, conforme Costa (2006), que deve existir uma proposta político-pedagógica orientada na socioeducaçáo, cujo objetivo seja preparar o apenado para o convívio social. 
Instamos que devemos ultrapassar os ditos regionalismos, individualismos e etnocentrismos, políticos e identitários, e investir em uma proposta política de respeito à diversidade em sua amplitude. Acreditamos que somente assim conseguiremos garantir o respeito à diferença e à democracia, compreendendo e valorizando os direitos dos outros e os nossos. Defendemos, sem sombra de dúvida, uma política de educação em espaços de privação de liberdade que não esteja dissociada de uma política, sendo essa nacional ou estadual, de EJA. Mas que a sua proposta pedagógica esteja contida no projeto político institucional da unidade penal na qual está inserida. Ou seja, passando a efetivamente ser uma escola $d a$ prisão.

\section{POR UMA POLÍTICA DE EDUCAÇÃO PARA ALÉM DO CÁRCERE}

A história da educação e do trabalho no cárcere remonta à da prisão nas sociedades ocidentais. É defendida na concepção de tratamento penitenciário, cujo objetivo, pelo menos no discurso, é o de reinserção social dos apenados, sendo reconhecida como política de ressocialização e tratamento penitenciário na execução penal.

Compreendendo o sistema penitenciário moderno com uma instituição social como tantas outras, reconhecendo a sua incompletude (tanto institucional, quanto profissional), cria-se uma nova dinâmica política e ideológica que prima pela não segregação total do indivíduo, pela concepção de que o ser humano vive em um constante processo de socialização e não de ressocialização e reinserção social. Reconhece-se que o papel do sistema de privação de liberdade, em suma, é de "sócio educar": do compromisso com a segurança da sociedade; e de promover a educação do delinquente para o convívio social (COSTA, 2006).

Dentro da discussão que assegura ao infrator a condição de sujeito frente ao aparato judicial, considerando-o como sujeito de direitos e de responsabilidades e como pessoa em condiçáo de desenvolvimento, negando a postura que considera o delito como manifestação patológica, emerge uma concepção de política de execução penal pautada em uma ideia moderna de "tratamento penitenciário", que implica 
e requer um conjunto articulado de açóes por parte do Estado e da sociedade, para a garantia de direitos fundamentais básicos (como o direito à sobrevivência, o direito ao desenvolvimento pessoal e social, além do direito à integridade física, psicológica e moral) através de políticas sociais básicas (de saúde, trabalho e educação); políticas de assistência social; políticas de proteção especial; e políticas de garantia de direitos.

Diante desaas questóes explicitadas, é necessário se colocar em prática o princípio de que o indivíduo privado de liberdade está, de fato, privado de direito de ir e vir, detendo ainda, liberdade de consciência, de expressão, de religião e de criação.

Embora seja positivo o papel da educação e do trabalho na política de reinserção social, não podemos simplesmente implementá-los para esse fim, mas, principalmente, que sejam garantidos como direitos elementares dos privados de liberdade como pessoas humanas. É importante que compreendamos a educação e o trabalho para o desenvolvimento humano, inclusive para a sua socialização.

Diante do novo paradigma de execuçâo penal, que contraria a perspectiva de instituição total ${ }^{5}$, primando pela incompletude institucional, ou seja, pela responsabilização da sociedade e do poder público pela política, é fundamental que as instituiçóes educacionais estejam realmente alinhadas com os propósitos estabelecidos, construindo e atualizando os seus projetos políticos pedagógicos de acordo com esses referenciais, de modo que a escola seja da prisão e não apenas uma escola na prisão. Uma escola que cumpra as determinaçóes legais ao mesmo tempo em que respeite as características e peculiaridades dos seus sujeitos, constituindo-se realmente em algo que esteja inserido na realidade prisional e que almeje desenvolver, por meio de propostas pedagógicas diferenciadas, as especificidades socioeducativas.

\section{CONSIDERAÇÕES FINAIS}

A escola, seja para crianças, jovens ou adultos, inclusive em ambientes de privaçáo de liberdade, deve ser concebida como um espaço de encontro e socialização ao mundo livre em que o saber é apenas um dos elementos para a sua constituição. Precisamos romper com a con- 
cepção tradicional e reducionista de escola, cujo objetivo central está na aquisição de conteúdos pragmáticos e muitas vezes descontextualizados do ambiente em que vivemos, principalmente do mundo moderno.

Para se alcançar tal objetivo no sistema prisional, torna-se fundamental a implementação de uma cultura em que realmente se privilegie uma política interdisciplinar de atendimento ao interno, onde não se torne utópica a participação, por exemplo, do assistente social na escola, do professor na assistência jurídica e vice-versa. Em linhas gerais, é preciso que se concretizem os "Planos Individuais de Atendimento", assim como os "Planos de Convivência Familiar e Comunitário".

É fundamental que se perceba que não é só com a criação de novas escolas, inclusive associadas ao ensino profissional, que resolveremos o problema da educaçáo para jovens e adultos privados de liberdade. É necessária uma concepção educacional que privilegie e ajude a desenvolver potencialidades e competências; que favoreçam a mobilidade social dos internos; que não os deixem se sentir paralisados diante dos obstáculos que serão encontrados na relação social.

Sem ter a pretensão de colocar um ponto final no debate, espero que este artigo venha contribuir com a referida discussão, possibilitando a ampliação da reflexão, bem como fornecendo subsídio para posteriores desdobramentos, principalmente que visem compreender que a educação no cárcere vai para além do ambiente prisional, sendo garantia de socialização para a vida, inclusive com liberdade.

\section{REFERÊNCIAS}

BRASIL. Lei n. 7.210, de 11 de julho de 1984. Lei de Execuçóes Penais. Diário Oficial da União, Brasília, DF, p. 10227, 13 jul. 1984. Seção 14.

. Constituição (1988). Constituição da República Federativa do Brasil. Brasília, DF: Senado Federal, 1988.

. Lei n. 9.394/1996, de 20 de dezembro de 1996. Lei de Diretrizes e Bases da Educação Nacional. Diário Oficial da Uniáo, Brasília, DF, p.27833, 23 dez. 1996. Seção 1. 
. Conferências Nacionais de Educação Básica (Documento final). Brasília, DF: MEC, 2008.

. Conferências Nacionais de Educação: construindo o sistema nacional articulado de educação - o Plano Nacional de Educação, Diretrizes e Estratégias de Ação (Documento final). Brasília, DF: MEC, 2010.

. Lei n. 12.433, de 29 de junho de 2011. Altera a Lei no 7.210, de 11 de julho de 1984 (Lei de Execuçáo Penal), para dispor sobre a remição de parte do tempo de execução da pena por estudo ou por trabalho. Diário Oficial da Uniáo, Brasília, DF, p. 1, 30 jun. 2011 a. Seção 1.

. Decreto n. 7.626, de 24 de novembro de 2011. Institui o Plano Estratégico de Educação no âmbito do Sistema Prisional. Diário Oficial da União, Brasília, DF, p. 2, 25 nov. 2011 b.

Conferências Nacionais de Educação: o PNE na articulação do sistema nacional de educação (Documento final). Brasília, DF: MEC, $2014 \mathrm{a}$.

. Lei no 13.005 de 25 de junho de 2014. Aprova o Plano Nacional de Educação. Diário Oficial da União, Brasília, DF, p. 1, 26 jun. 2014b. Seção 1, Edição Extra.

- Ministério da Justiça. Departamento Penitenciário Nacional. Levantamento Nacional de Informaçóes Penitenciárias INFOPEN - Junho de 2014. Brasília, DF: MJ/DEPEN, 2015.

CONSELHO NACIONAL DE EDUCAÇÃO (CNE). Resolução CNE/CEB n. 2, de 2010. Dispóe sobre as Diretrizes Nacionais para a oferta de educação para jovens e adultos em situação de privação de liberdade nos estabelecimentos penais. Brasília, DF: CNE, 2010.

CONSELHO NACIONAL DE POLÍTICA CRIMINAL E PENITENCIÁRIA (CNPCP). Resolução CNPCP n. 3, de 2009. Dispóe sobre as Diretrizes Nacionais para a Oferta de Educação nos estabelecimentos penais. Brasília, DF: CNPCP, 2009.

. Resolução CNPCP n. 09, de 2011. Diretrizes básicas para arquitetura prisional. Brasília, DF: CNPCP, 2011.

COSTA, A.C.G. Socioeducação: estrutura e funcionamento da comunidade educativa. Brasília: Secretaria Especial de Direitos Humanos, 2006.

Política pública de educação penitenciária: contribuição para o diagnóstico da experiência do Rio de Janeiro. 2003. 131f. Dissertação (mestrado) 
- Programa de Pós-graduação em Educação. Pontifícia Universidade Católica do Rio de Janeiro, Rio de Janeiro.

- Sistema penitenciário brasileiro: a educação e o trabalho na Política de Execuçáo Penal. Petrópolis: DP\&A, 2012.

A diversidade do sujeitos da educaçáo de jovens e adultos. In: MEDEIROS, C.C; GASPARELLO, A; BARBOSA, J.L. Educação de jovens, adultos e idosos: saberes, sujeitos e práticas. Niterói: UFF/Cead, 2015, p. 157-170.

JULIÃO, E.F.; PAIVA, J. Políticas de educação para jovens e adultos em situação de privação de liberdade no Brasil: questóes, avanços e perspectivas na diversidade de sujeitos de direito. In: (Org). Políticas de educação para jovens e adultos: construindo diálogos com as Américas. Petrópolis: De Petrus; FAPERJ, 2015, p. 125-149.

LEME, J.A.G. A cela de aula: tirando a pena com letras - uma reflexão sobre o sentido da educação nos presídios. In: ONOFRE, E.M.C. (Org.). Educação escolar entre as grades. São Carlos: EdUFSCAR, 2007. p. 111-160.

PENNA, M.G.O. O exercício docente por monitores-presos e o desenvolvimento do processo formativo. In: ONOFRE, E.M.C. (Org.). Educaçấo escolar entre as grades. São Carlos: EdUFSCAR, 2007. p. 77-91.

UNESCO. Educando para a liberdade: trajetórias, debates e proposiçóes de um projeto para a educação nas prisóes brasileiras. Brasília: UNESCO, 2006.

. Educação em prisóes na América Latina: direito, liberdade e cidadania. Brasília: UNESCO, 2009.

\section{NOTAS}

1. Esta experiência, sem qualquer apoio da Secretaria de Estado de Educação de São Paulo, perdurou até 2010, com a aprovação das Diretrizes Curriculares Nacionais pelo Conselho Nacional de Educação. Por não fazer parte da proposta política do sistema educacional paulista, os internos não eram certificados.

2. A primeira experiência oficial de escola oferecendo vagas para turmas de ensino médio no país ocorreu em 2000 no estado do Rio de Janeiro, na entáo escola Mário Quintana, no Complexo Penitenciário da Frei Caneca.

3. O ensino básico compreende a educação infantil, o ensino fundamental e o médio. Atualmente compreende-se por ensino fundamental os nove anos de ensino inicial. 
4. A Lei de Execução Penal visando a "individualização da pena" prevê que a Comissão Técnica de Classificação deve apresentar propostas de "Plano de Atendimento Individualizado" aos internos, levando-se em consideração a pessoa humana, suas limitaçôes e especificidades.

5. Segundo Goffman - em Manicômios, prisöes e conventos. São Paulo: Perspectiva, 1961 —, são estabelecimentos fechados em que o seu caráter total é simbolizado pela barreira à relação social com o mundo externo e por proibições à saída que muitas vezes estão incluídas no esquema físico - por exemplo, portas fechadas, paredes altas, arame farpado, fossos, água, florestas ou pântanos.

Recebido em 11 de setembro de 2015.

Aceito em 22 de fevereiro de 2016. 